\title{
Analisis determinasi pertumbuhan ekonomi dan kemiskinan
}

\author{
Pilipus Bambang Wahyono Putro ${ }^{1}$, Sri Mintarti ${ }^{2}$, Adi Wijaya ${ }^{3}$ \\ Magister Ilmu Ekonomi, Fakultas Ekonomi dan Bisnis Universitas Mulawarman, Samarinda. \\ ${ }^{1}$ Email: pilipus bambang.wahyono.putro@mhs.feb.unmul.ac.id \\ ${ }^{2}$ Email: sri.mintarti@feb.unmul.ac.id \\ 3Email: adi.wijaya@feb.unmul.ac.id
}

\begin{abstract}
Abstrak
Penelitian untuk menganalisis faktor-faktor yang mempengaruhi kemiskinan yang terjadi di Provinsi Kalimantan Timur. Dengan variabel independen Belanja modal pemerintah, IPM, dan Ketimpangan pendapatan/gini ratio, dan variabel intervening PDRB, selain itu juga untuk menguji dan menganalisis seberapa besar pengaruh masing-masing variabel independen terhadap variabel dependen. Alat analisis yang digunakan adalah analisis kuantitatif yang menggunakan analisis jalur (path analysis). Analisis jalur digunakan untuk mengetahui seberapa besar pengaruh Belanja modal pemerintah (X1), IPM (X2), dan Ketimpangan pendapatan/gini ratio (X3), terhadap PDRB (YI) serta dampaknya terhadap variabel Kemisinan (Y2) di Provinsi Kalimantan Timur. Berdasar hasil analisis, variabel Belanja modal pemerintah, IPM, dan Ketimpangan pendapatan/ gini ratio secara bersamasama berpengaruh terhadap Kemiskinan di Provinsi Kalimantan Timur baik secara langsung maupun secara tidak langsung melalui variabel antara PDRB.
\end{abstract}

Kata Kunci: Determinasi pertumbuha ekonomi

\section{Analysis of determination of economic growth and poverty}

Research to analyze the factors affecting poverty that occurred in East Kalimantan Province. With independent variables Government capital expenditure, HDI, and income inequality / gini ratio, and intervening variables PDRB, but also to test and analyze how much influence each independent variable to the dependent variable. The analytical tool used is a quantitative analysis using path analysis. Path analysis is used to find out how big influence of government capital expenditure (X1), IPM (X2), and income inequality / gini ratio (X3), to PDRB (YI) and its impact on variable of Kemisinan (Y2) in East Kalimantan Province. Based on the results of the analysis, variables of government capital expenditure, HDI, and income inequality / gini ratio jointly affect poverty in East Kalimantan Province either directly or indirectly through variables between PDRB. Keywords: Determination of economic growth 


\section{PENDAHULUAN}

Kemiskinan di Kaltim ditandai oleh adanya ketimpangan antar wilayah. Kemiskinan di kawasan perbatasan, pedalaman dan tertinggal jumlah penduduk miskin cukup tinggi. Terdapat 7 (tujuh) kabupaten/kota yang mengalami kecenderungan peningkatan penduduk miskin yaitu kabupaten Berau, Nunukan, Penajam Paser Utara, Tana Tidung, kota Balikpapan, Samarinda dan Bontang.

Penurunan jumlah penduduk miskin ini sangat tidak sebanding dengan penerimaan dan pengeluaran pemerintah Kaltim yang relatif cukup besar, terutama sejak tahun 2007-2011. Kaltim merupakan salah satu provinsi yang memiliki Anggaran Pendapatan Dan Belanja Daerah (APBD) relatif cukup besar. Kualitas sumber daya manusia juga dapat menjadi faktor penyebab terjadinya penduduk miskin. Kualitas sumber daya manusia dapat dilihat dari indeks kualitas hidup/indeks pembangunan manusia. Rendahnya Indeks Pembangunan Manusia (IPM) akan berakibat pada rendahnya produktivitas kerja dari penduduk. Produktivitas yang rendah berakibat pada rendahnya perolehan pendapatan.

Permasalahan ketimpangan pendapatan tidak dapat dipisahkan dari permasalahan kemiskinan, biasanya terjadi pada negara miskin dan berkembang. Menurut Arsyad (1997), banyak negara sedang berkembang yang mengalami tingkat pertumbuhan ekonomi tinggi pada tahun 1960-an mulai menyadari bahwa pertumbuhan yang semacam itu hanya sedikit manfaatnya dalam memecahkan masalah kemiskinan. Di negara-negara miskin yang menjadi perhatian utama adalah masalah pertumbuhan versus distribusi pendapatan (Putra, 2011).

Dengan melihat dan mengacu pada uraian tersebut di atas, maka, peneliti tertarik untuk melakukan penelitian dengan judul "Analisis Determinasi Pertumbuhan Ekonomi dan Kemiskinan di Provinsi Kalimantan Timur".

\section{METODE}

Dalam menganalisa data digunakan teknik analisa jalur (path analysis) dalam menguji besarnya pengaruh yang ditunjukkan oleh koefisien jalur pada setiap diagram jalur dari hubungan kausal antara variabel tingkat Pengeluaran Pemerintah, terhadap pertumbuhan ekonomi terhadap tingkat pengangguran di Kutai Barat.

1) Sub struktur -1

Melihat pengaruh langsung dari variabel Pengeluaran Pemerintah (X1), IPM (X2), dan Ketimpangan Pendapatan (X3) terhadap tingkat pengangguran (Y1)

$$
Y_{1}=\alpha_{0}+\alpha_{1} X_{1}+\alpha_{2} X_{2}+\alpha_{3} X_{3}+\mu_{1}
$$

2) Sub Struktur -2

Melihat pengaruh langsung dari variabel tingkat Pengeluaran Pemerintah (X1), IPM (X2), dan Ketimpangan Pendapatan (X3) dan variabel pertumbuhan ekonomi (Y1) terhadap tingkat kemiskinan (Y2).

$$
Y_{2}=\beta_{0}+\beta_{1} X_{1}+\beta_{2} X_{2}+\beta_{3} X_{3}+\beta_{4} Y_{1}+\mu_{2}
$$

\section{Hipotesa Penelitian}

1) Pengeluaran pemerintah secara langsung berpengaruh positif dan signifikan terhadap pertumbuhan ekonomi di Provinsi Kalimantan Timur.

2) IPM secara langsung berpengaruh positif dan signifikan terhadap pertumbuhan ekonomi di Provinsi Kalimantan Timur.

3) Ketimpangan pendapatan secara langsung berpengaruh negatif dan signifikan terhadap pertumbuhan ekonomi di Provinsi Kalimantan Timur.

4) Pengeluaran pemerintah secara langsung berpengaruh negatif dan signifikan terhadap kemiskinan di Provinsi Kalimantan Timur.

5) IPM secara langsung berpengaruh negatif dan signifikan terhadap kemiskinan di Provinsi Kalimantan Timur.

6) Ketimpangan pendapatan secara langsung berpengaruh positif dan signifikan terhadap kemiskinan di Provinsi Kalimantan Timur. 
7) Pertumbuhan ekonomi secara langsung berpengaruh negatif dan signifikan terhadap kemiskinan di Provinsi Kalimantan Timur.

8) Pengeluran pemerintah secara tidak langsung berpengaruh negatif dan signifikan terhadap kemiskinan melalui pertumbuhan ekonomi di Provinsi Kalimantan Timur.

9) IPM secara tidak langsung berpengaruh negatif dan signifikan terhadap kemiskinan melalui pertumbuhan ekonomi di Provinsi Kalimantan Timur.

10) Ketimpangan pendapatan secara tidak langsung berpengaruh positif dan signifikan terhadap kemiskinan melalui pertumbuhan ekonomi di Provinsi Kalimantan Timur.

\section{HASIL DAN PEMBAHASAN}

\section{Analisis}

1) $\mathrm{Y} 1=0.972 \mathrm{X} 1-0.466 \mathrm{X} 2-0.196 \mathrm{X} 3$

2) $\mathrm{Y} 2=0.317 \mathrm{X} 1-0.445 \mathrm{X} 2+0.042 \mathrm{X} 3-1.239 \mathrm{Y} 1$

3) Pengaruh tak langsung $\mathrm{X} 1 \mathrm{ke} \mathrm{Y} 2$ melalui $\mathrm{Y} 1$ sebesar $-1,2568$.

4) Pengaruh tak langsung $X 2$ ke $Y 2$ melalui $Y 1$ sebesar 0,560254 .

5) Pengaruh tak langsung $X 3$ ke $Y 2$ melalui $Y 1$ sebesar 0,25343.

\section{Pembahasan}

1) Belanja modal pemerintah berpengaruh positif dan signifikan terhadap PDRB ADHK di Provinsi Kalimantan Timur. Hal ini sesuai teori menurut Sukirno (2000) Kegiatan investasi memungkinkan suatu masyarakat terus menerus meningkatkan kegitan ekonomi dan kesempatan kerja, meningkatkan pendapatan nasional dan meningkatkan taraf kemakmuran masyarakat.

2) IPM secara individual berpangaruh positif dan signifikan terhadap PDRB ADHK di Provinsi Kalimantan Timur. Pembangunan ekonomi atau pertumbuhan ekonomi merupakan persyaratan bagi tercapainya pembangunan manusia, karena denggan pembangunan ekonomi terjamin peningkatan produktifitas dan peningkatan pendapatan melalui kesempaten kerja. Hipotesis dampak merembes ke bawah (trickle down effect) menyebutkan bahwa pertumbuhan ekonomi yang cepat akan menetes ke pembangunan manusia.

3) Ketimpangan pendapatan secara individual tidak berpengaruh signifikan terhadap PDRB ADHK di Provinsi Kalimantan Timur. disebabkan derajat kesenjangan pendapatan sangat mempengaruhi kehidupan perekonomian masyarakat di Provinsi KalimantanTimur. Ketimpangan pendapatan di Provinsi Kalimantan Timur secara keseluruhan masih berada dalam batas "wajar" yaitu sebesar 0.33 di tahun 2014 dan terjadi penurunan pada tahun 2015 menjadi 0,32.

4) Pengeluaran pemerintah belanja modal berpengaruh langsung dan tidak signifikan terhadap kemiskinan. Hal ini bertentangan dengan tujuan pembangunan dimana pemerintah selalu menginginkan bahwa kemiskinan itu semakin menurun setiap tahunnya atau dengan kata lain bahwa pengeluaran pemerintah dalam bentuk belanja modal tidak punya efek terhadap penurunan tingkat kemiskinan. Hal tersebut terjadi karena pada saat pemerintah mengeluarkan belanja modal dalam bentuk pembangunan infrastruktur tidak melibatkan masyarakat miskin secara langsung, akan menciptakan lapangan kerja secara umum. Hasil temuan ini juga dapat menjelaskan bila pembangunan infrastruktur yang menggunakan dana dari pengeluaran pemerintah lebih banyak di keluarkan di daerah perkotaan maka masyarakat miskin di pedesaan tidak akan ikut berpartisipasi dalam proyek tersebut. Kedepan pemerintah Provinsi Kalimantan Timur dalam penetapan kebijakan untuk menurunkan kemiskinan itu hendaknya menggunakan alokasi dana yang dikhususkan untuk menurunkan tingkat kemisknan agar apa yang diinginkan oleh pemerintah dan oleh masyarakat pada umumnya dapat tercapai yaitu penurunan tingkat kemiskinan yang signifikan.

5) Indeks Pembangunan Manusia berpengaruh positif dan signifikan terhadap kemiskinan. Rendahya kualitas SDM Provinsi Kalimantan Timur berhubungan dengan permasalahan pokok antara lain rendahnya akses dan mutu pendidikan serta akses mutu pelayanan kesehatan masih perlu ditingkatkan. 
6) Ketimpangan pendapatan tidak berpengaruh signifikan terhadap kemiskinan atau jika ketimpangan pendapatan naik maka kemiskinan mengalami peningkatan. Hal ini disebabkan ketidakmerataan dan kemiskinan, distribusi pendapatan dapat dijadikan dasar untuk menganalisis masalah pembangunan yang lebih khusus seperti pertumbuhan penduduk, pengangguran, pembangunan pedesaan, pendidikan di Provinsi Kalimantan Timur.

7) PDRB ADHK berpengaruh negatif dan signifikan terhadap kemiskinan. Dengan kondisi perkembangan ekonomi Provinsi Kalimantan Timur telah melalui beberapa fase perkembangan ekonomi yang kurang sehat dan berkualitas. Hasil penelitian ini sesuai dengan pertumbuhan ekonomi menurut Kuznet dikutip dari Tambunan (2001) dalam Wijayanto (2010) memiliki korelasi yang kuat terhadap kemiskinan. Pertumbuhan ekonomi pada awal menyebabkan tingkat kemiskinan cenderung meningkat namun pada saat mendekati tahap akhir terjadi terjadi pengurangan tingkat kemiskinan secara berkesinambungan. Dengan demikian, dapat dikatakan pertumbuhan ekonomi memiliki pengaruh yang negatif terhadap kemiskinan.

8) pengeluaran pemerintah Provinsi Kalimantan Timur dalam konteks ini sebagai penyedia kewajiban publik untuk peningkatan pendidikan adalah elemen penting untuk memerangi kemiskinan. Sehingga dapat menyentuh langsung masyarakat pelosok dan meningkatkan kesejahteraan masyarakat, serta menumbuhkan pertumbuhan ekonomi. Hasil ini sesuai dengan hasil penelitian (Waridin,2011) Investasi publik akan memberikan pelayanan kepada masyarakat yang lebih merata sehingga sumber daya manusia (SDM) yang handal menjadi semakin bertambah.

9) Indeks Pembangunan Munusia di Provinsi Kalimantan Timur selalu indentik dengan kemiskinan oleh sebab itu IPM merupakan indeks komposit dari tiga variabel kesejahteraan yaitu umur panjang, pendidikan dan standar hidup layak. Sehingga peningkatan nilai indeks akan mencerminkan peningkatan kesejahteraan masayakat Provinsi Kaliamantan Timur. Pendapat ini sesuai dengan penelitian Lanjouw, dkk. (2001) menyatakan pembangunan manusia di Indonesia adalah identik dengan pengurangan kemiskinan.

10) Ketimpangan pendapatan di Provinsi Kalimantan Timur menjadi perhatian khusus pemerintah. Dimana penghapusan kemiskinan dan ketidak merataan pendapatan merupakan salah satu inti masalah pembangunan daerah. Dan dicari solusi agar sektor-sektor padat modal yang berperan dalam pembentukan PDRB. Hasil penelitian ini sesuai dengan Todaro (2000), Pengaruh antara ketimpangan distribusi pendapatan terhadap kemiskinan dipengaruhi oleh adanya peningkatan jumlah penduduk. Pertambahan penduduk cenderung berdampak negatif terhadap penduduk miskin, terutama bagi mereka yang sangat miskin. Sebagian besar keluarga miskin memiliki jumlah anggota keluarga yang banyak sehingga kondisi perekonomian mereka yang berada di garis kemiskinan semakin memburuk seiring dengan memburuknya ketimpangan pendapatan atau kesejahteraan.

\section{SIMPULAN}

Dari hasil analisis penelitian ini maka dapat disimpulkan beberapa hal sebagai berikut:

1. Belanja Modal Pemerintah berpengaruh langsung dan signifikan terhadap PDRB ADHK di Provinsi Kalimantan Timur.

2. Indeks Pembangunan Manusia berpengaruh langsung dan signifikan terhadap PDRB ADHK di Provinsi Kalimantan Timur

3. Ketimpangan pendapatan tidak berpangaruh signifikan secara langsung terhadap PDRB ADHK di Provinsi Kalimantan Timur

4. Pengeluaran pemerintah belanja modal tidak berpengaruh signifikan secara langsung terhadap kemisknan di Provinsi Kalimantan Timur

5. Indeks pembangunan manusia berpengaruh negatif secara langsung dan signifikan terhadap kemisknan di Provinsi Kalimantan Timur

6. Ketimpangan pendapatan (gini ratio) tidak berpengaruh signifikan secara langsung terhadap kemisknan di Provinsi Kalimantan Timur 
7. PDRB ADHK berpengaruh negatif secara langsung dan signifikan terhadap Kemiskinan di Provinsi Kalimantan Timur .

8. Pengeluaran pemerintah belanja modal berpengaruh tidak langsung dan tidak signifikan terhadap terhadap kemiskinan melalui PDRB ADHK

9. Indeks Pembangunan Manusia berpengaruh langsung dan signifikan terhadap terhadap kemiskinan melalui PDRB ADHK

10. Ketimpangan Pendapatan berpengaruh langsung dan signifikan terhadap terhadap kemiskinan melalui PDRB ADHK

\section{DAFTAR PUSTAKA}

Badan Pusat Statistik. 2012. Data dan Informasi Kemiskinan 2008-2012. Jakarta: Badan Pusat Statistik Indonesia.

Badan Pusat Statistik. 2012. Perkembangan Beberapa Indikator Utama Sosial - Ekonomi Indonesia Berbagai Edisi. Jakarta: Badan Pusat Statistik Indonesia

Boediono, 1999, Teori Pertumbuhan Ekonomi, Yogyakarta: BPFE

Cholili, Fatkhul Mufid .2014. Analisis Pengaruh Pengangguran, Produk Domestik Regional Bruto (PDRB), dan Indeks Pembangunan Manusia (IPM) Terhadap Jumlah Penduduk Miskin (Studi Kasus 33 Provinsi Di Indonesia). Universitas Diponegoro. Semarang

Deni Tisna A. 2008. Pengaruh Ketidakmerataan Distribusi Pendapatan, Pertumbuhan Ekonomi dan Pengangguran Terhadap Tingkat Kemiskinan di Indonesia tahun 2003-2004. Kumpulan skripsi UNDIP: Semarang.

Djojohadikusumo, S. 1989. Ekonomi Pembangunan: Pengantar Ekonomi Pembangunan. Jakarta.

Dumairy, 1999, Perekonomian Indonesia. Penerbit Erlangga, Jakarta.

Jundi, Musa Al, 2014. Analisis Faktor Yang Mempengaruhi Tingkat Kemiskinan Provinsi-Provinsi Di Indonesia. Fakultas Ekonomika Dan Bisnis Universitas Diponegoro. Semarang

Kiswanto, Muhammad, 2014. Pengaruh Pengeluaran Pemerintah terhadap Pencapaian Tujuan Pembangunan melalui Investasi, Mutu Sumberdaya Manusia, Pertumbuhan Ekonomi dan Kesempatan Kerja di Kalimantan Timur. Universitas Hasanuddin Makassar

Lanjouw Petter, dkk. Poverty Education and health in Indonesia: Who Benefits From Public Spending. World Bank Discussion Paper No.339, Washington. 2001.

Arsyad, Lincolin. 1999. Ekonomi Pembangunan. Edisi Keempat, Bagian Penerbitan STIE YKPN. Yogyakarta.

Mahmudi. 2007. Manajemen Kinerja Sektor Publik. UPP. STIM YKPN. Yogyakarta.

Mankiw, Gregory. 2003. Teori Makro Ekonomi. Penerjemah: Chriswan Sungkono. PT Erlangga. Jakarta

Mudrajad Kuncoro. 2000. Ekonomi Pembangunan: Teori, Masalah, dan Kebijakan. UPP AMP YKPN.

Musgrave, Richard. A dan Peggy B Musgrave. 1989. Public Finance in Theory and Practise. Fifth Edition, McGraw-Hill Book, International Edition, 1989.

Paul Spicker. 2002. Poverty and The Walfare State: Displling The Myths, A Catalyst Working Paper, London: Catalyst.

Prastyo, Adit Agus. 2010. Analisis Faktor-Faktor Yang Mempengaruhi Tingkat Kemiskinan. http://eprints.undip.ac.id. 
Putra, Linggar Dewangga dan Achma Hendra Setiawan (2011). Analisis Pengaruh Ketimpangan Distribusi Pendapatan Terhadap Jumlah Penduduk Miskin Di Provinsi Jawa Tengah Periode 2000 - 2007. Fakultas Ekonomi. Universitas Diponegoro. Semarang.

Robert Chamber. 2010. Paradigms, Poverty and Adaptive Pluralism. WORKING PAPER Volume 2010 Number 344. Institute of Development Studies at the University of Sussex, UK

Rusdarti dan Lesta Karolina Sebayang. 2013. Faktor-Faktor Yang Mempengaruhi Tingkat Kemiskinan di Provinsi Jawa Tengah. Jurnal Economia, Volume 9, Nomor 1, April 2013

Rustiono, 2008, Analisis Pengaruh Pengeluaran Pemerintah Di Sektor Pendidikan dan Kesehatan Terhadap Pengentasan Kemiskinan Melalui Peningkatan Pembangunan Manusia di Provinsi Jawa Tengah.Tesis pada PPS-Unej, Jember.

Saputra, W.A. 2011. Analisis Pengaruh Jumlah Penduduk, PDRB, IPM, Pengangguran Terhadap Tingkat Kemiskinan Di Kabupaten / Kota Jawa Tengah. Universitas Diponegoro. Semarang.

Siregar, H. dan Dwi Wahyuniarti. 2007. Dampak Pertumbuhan Ekonomi Terhadap Penurunan Jumlah Penduduk Miskin. http://pse.litbang.deptan.go.id/ind/pdffiles/PROS_2008_MAK3.pdf.

Sukirno, Sadono. 2000. Makroekonomi Modern. Raja Grafindo Persada. Jakarta.

Tambunan, Tulus. 2001. Perekonomian Indonesia, Beberapa Masalah Penting. Ghalia Indonesia. Jakarta.

Todaro, Michael. (2000). Pembangunan Ekonomi di Dunia Ketiga. Edisi ke-7 (Terjemahan Bahasa Indonesia). PT Erlangga. Jakarta

Widodo, Adi, Waridin, dan Johanna Maria K. 2011. Analisis Pengaruh Pengeluaran Pemerintah Di Sektor Pendidikan Dan Kesehatan Terhadap Pengentasan Kemiskinan Melalui Peningkatan Pembangunan Manusia Di Provinsi Jawa Tengah. BPKP Perwakilan Jawa Tengah. Fakultas Ekonomika dan Bisnis Universitas Diponegoro. Semarang

Wijayanto, Ravi Dwi. 2010. Analisis Pengaruh PDRB, Pendidikan dan Pengangguran Terhadap Kemiskinan di Kabupaten/Kota Jawa Tengah Tahun 2005-2008. http://eprints.undip.ac.id.

Yani Mulyaningsih. 2008. Pengaruh Pengeluaran Pemerintah di Sektor Publik Terhadap Peningkatan Pembangunan Manusia dan Pengurangan Kemiskinan. Fakultas Ekonomika dan Bisnis Universitas Diponegoro. Semarang

Yanti Nurfitri, 2009. Pengaruh Pertumbuhan Ekonomi, Inflasi, Dan Tingkat Kesempatan Kerja Terhadap Tingkat Kemiskinan Di Indonesia Tahun 1999-2009. Yogyakarta: UPN Yogyakarta. 